\title{
Review
}

\section{Yeast unfolds the road map toward $\alpha$-synuclein- induced cell death}

\author{
V Franssens ${ }^{1}$, E Boelen ${ }^{1}$, J Anandhakumar ${ }^{1}$, T Vanhelmont ${ }^{1}$, S Büttner ${ }^{2}$ and J Winderickx ${ }^{*, 1}$
}

The budding yeast Saccharomyces cerevisiae has contributed significantly to our current understanding of eukaryotic cell biology. It served as a tool and model for unraveling the molecular basis of a wide variety of cellular phenomena, which seem to be conserved in other organisms. During the last decade, yeast has also extensively been used to study the mechanisms underlying several human diseases, including age-associated neurodegenerative disorders, such as Parkinson's, Huntington's and Alzheimer's disease. In this review, we focus on a yeast model for synucleinopathies and summarize recent studies that not only provided new clues on how the misfolding of $\alpha$-synuclein ( $\alpha$-syn) triggers toxicity and eventually cell death, but that also led to the identification of conserved suppressor proteins, which are effective in protecting cells, including neurons, from the $\alpha$-syn-induced cytotoxicity.

Cell Death and Differentiation (2010) 17, 746-753; doi:10.1038/cdd.2009.203; published online 18 December 2009

The assembly of misfolded proteins or derived peptides into amyloidic aggregates is a hallmark of neurodegenerative disorders, such as Parkinson's (PD), Huntington's and Alzheimer's disease. The aggregation process adversely affects neuronal functions, thereby triggering increased oxidative stress and eventually cell death. In healthy neurons, misfolded proteins and aggregates do not accumulate because cells have different protein quality control (QC) systems. One of these systems involves molecular chaperones, which detect misfolded proteins and promote their refolding and repair. ${ }^{1,2}$ When this system fails, aberrant proteins are marked for degradation through the ubiquitinproteasome system (UPS) or the autophagy-lysosome pathway. ${ }^{3}$ In addition, cells have defense mechanisms to cope with and neutralize normal levels of reactive oxygen species (ROS), which otherwise would contribute to protein damage and misfolding. ${ }^{4}$ The close mutual relationship between protein misfolding and ROS seems to be one of the important pathogenic triggers of neurodegeneration. Indeed, many mutations associated with neurodegenerative disorders either generate proteins or peptides with a higher propensity to selfassemble, or they affect crucial functions for protein $Q C$ or the antioxidant defense. ${ }^{5-7}$

Handling protein misfolding and oxidative stress is essential for all cells and the underlying mechanisms originated early in evolution. In fact, much of our understanding of these processes came from studies performed in the baker's yeast Saccharomyces cerevisiae. ${ }^{8-10}$ Hence, it is not surprising that fundamental aspects related to misfolding of disease proteins and amyloid toxicity can be recapitulated in this lower eukaryote. Furthermore, neurodegenerative diseases show an age-dependent incidence and it is speculated that this is, at least in part, due to accumulation of aberrant proteins concomitant with a declining capacity of the protein QC systems as well as to increasing ROS levels that overwhelm the antioxidant defense mechanisms in postmitotic neurons. ${ }^{11,12}$ In this respect, the yeast chronological aging or postmitotic survival model provides a valuable tool to study these age-related aspects. ${ }^{13,14}$ In this review, we describe the use of yeast models to study the toxicity of $\alpha$-synuclein ( $\alpha$-syn), a protein with a central role in the etiology of PD.

\section{$\alpha$-Syn and PD}

$\mathrm{PD}$ is the most common neurodegenerative movement disorder affecting more than $4 \%$ of the population by the age of 85 years. The disease is clinically characterized by resting tremors, muscle rigidity, bradykinesia and postural instability. The neuropathological basis of the disease is the selective and progressive degeneration of dopaminergic neurons in the substantia nigra pars compacta. The dying neurons are characterized by the presence of Lewy bodies (LBs) and Lewy neurites, which represent proteinaceous inclusions that contain mainly fibrillar $\alpha$-syn. ${ }^{15}$ Although most cases of PD are sporadic/idiopathic with a late onset and unknown etiology, several studies contributed to the

${ }^{1}$ Functional Biology, Department of Biology, Katholieke Universiteit Leuven, Heverlee, Belgium and ${ }^{2}$ Institute of Molecular Biosciences, University of Graz, Graz, Austria ${ }^{*}$ Corresponding author: J Winderickx, Functional Biology, Department of Biology, Katholieke Universiteit Leuven, Kasteelpark Arenberg 31, 3001 Heverlee, Belgium. Tel: + 3216 321516; Fax: + 3216 321967; E-mail: joris.winderickx@bio.kuleuven.be

Keywords: Parkinson's disease; $\alpha$-syn; yeast; vesicular trafficking; oxidative stress; apoptosis

Abbreviations: ERAD, ER-associated protein degradation; LB, Lewy bodies; NatB, N-terminal acetyltransferase complex B; PD, Parkinson's disease; PDI, protein disulfide isomerase; QC, quality control; ROS, reactive oxygen species; UPS, ubiquitin-proteasome system; UPR, unfolded protein response

Received 03.8.09; revised 26.10.09; accepted 02.11.09; Edited by F Madeo; published online 18.12.09 
identification of mutations in genes associated with familial cases of parkinsonism. For six genes, the association with PD is well established. Besides $\alpha$-syn, these include the PTENinduced kinase 1 (PINK1), the leucine-rich repeat kinase 2 (LRRK2), the E3-ubiquitin-ligase parkin, the lysosomal P-type ATPase, ATP13A2, and finally, the putative redox sensor DJ-1. For other genes, such as the serine protease Omi/HtrA2 or the ubiquitin carboxy-terminal esterase, $\mathrm{UCH}-\mathrm{L} 1$, the genetic evidence is less clear and based on a few cases. These genes link $P D$ to protein $Q C$ systems, oxidative stress and mitochondrial dysfunction, as shown in Figure $1 .{ }^{16}$

The finding that $\alpha$-syn was the main constituent of LB led to the hypothesis that this protein is causatively linked to PD. This was confirmed as three missense mutations in $\alpha$-syn, A30P, E46K and A53T, as well as duplication or triplication of the $\alpha$-syn locus, are associated with early onset familial cases

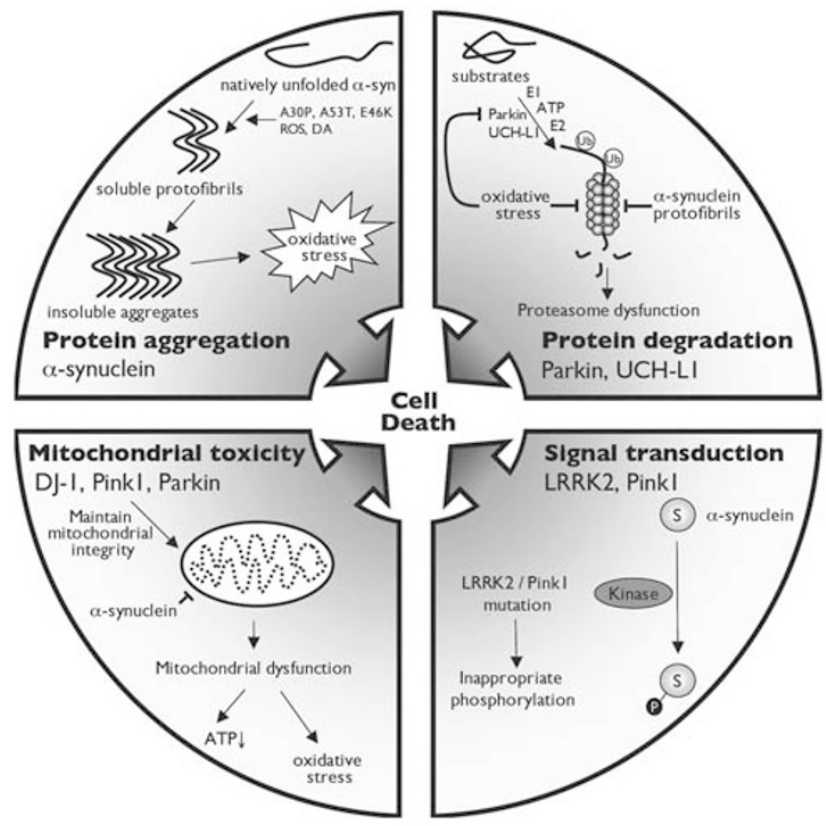

Figure 1 Pathways leading to neuronal cell death in PD. The identification of genes associated with PD was of great importance to gain insights into the molecular mechanisms underlying neurodegeneration in PD as it defined four major themes leading to neuronal demise; that is, protein aggregation, protein degradation, mitochondrial dysfunction and signal transduction. For protein aggregation, the key player leading to cell death is $\alpha$-syn. Its aggregation coincides with ROS formation and seems to influence several crucial functions such as vesicular trafficking, mitochondrial function and proteolytic machinery. In healthy cells, the accumulation of toxic proteins, such as misfolded $\alpha$-syn, is prevented by their degradation in proteasomal machinery, which involves the PD-associated genes Parkin and UCHL-1. However, oligomeric and fibrillated $\alpha$-syn cannot be accessed by the proteasome. In addition, the presence of oxidative stress further compromises the UPS, either directly or indirectly through impairment of Parkin. The PD-associated genes, DJ-1 and Pink1, interact with Parkin and were shown to have a role in maintaining mitochondrial integrity. Hence, mutations in these genes lead to mitochondrial dysfunction, resulting in a decline in ATP production, an increase in oxidative stress and, eventually, cell death. Some studies suggest that $\alpha$-syn translocates to the mitochondria and that this may directly impair mitochondrial activity. Finally, the importance of regulated protein phosphorylation in the induction of cell death became more prominent on identification of PD-associated mutations in the kinases Pink1 and LRRK2. Most recently, it has been shown that mutant LRRK2 has an increased capacity to phosphorylate $\alpha$-syn at serine 129 in vitro. See main text for references of parkinsonism. Although the cellular function of $\alpha$-syn is still being investigated, a regulatory role in dopamine neurotransmission and synaptic vesicular recycling has been suggested. ${ }^{15}$ Recently, it was proposed that $\alpha$-syn is involved in vesicular priming and vesicular membrane fusion, ${ }^{17}$ possibly by ameliorating complex formation of the plasma membrane and vesicular SNARE proteins. ${ }^{18}$ Other studies have suggested that the protein may have chaperone activity ${ }^{19}$ or fulfills a regulatory role in lipid metabolism. ${ }^{20}$

$\alpha$-Syn is an intrinsically unfolded protein of 140 amino acids that has the propensity to self-assemble and to form oligomeric protofibrils that can further mature into different types of fibers and aggregates. The exact mechanism that initiates this process is still elusive and, besides membrane binding, ${ }^{21}$ it may involve tyrosine nitration, ${ }^{22}$ phosphorylation $^{23}$ or even C-terminal truncation. ${ }^{24}$ In addition, oxidative stress seems to stimulate $\alpha$-syn oligomerization. ${ }^{25}$

To date, it is still a matter of debate whether the soluble protofibrils or the maturated $\alpha$-syn aggregates incite neurotoxicity. ${ }^{15,26}$ Some studies suggest that the matured aggregates are inert or even have a protective role as they set aside harmful soluble protofibrils. ${ }^{27,28}$ One proposed mechanism by which protofibrils could be toxic is that they form pores and permeabilize vesicular membranes, thereby causing leakage of dopamine metabolites, which in turn cause oxidative damage. $^{29}$ In addition, binding to mitochondrial membranes leading to mitochondrial dysfunction, ${ }^{30,31}$ deregulation of the UPS, ${ }^{32}$ aberrant ER-associated protein degradation (ERAD) and a sustained unfolded protein response (UPR) ${ }^{33,34}$ have been proposed. Although the mechanism for execution of $\alpha$-syn-induced cell death is not known, most evidence suggests that neuronal demise in PD involves apoptosis. ${ }^{35,36}$

\section{Modeling $\alpha$-Syn-Induced Toxicity in Yeast}

Although the yeast $S$. cerevisiae does not have any synuclein ortholog, several studies have validated the use of this organism as a powerful model to gain further insights and uncover new clues for the pathophysiology of $\alpha$-syn (Table 1). Indeed, when expressed in this yeast, human wild-type $\alpha$-syn (WT-syn) and its clinical A53T mutant are delivered to the plasma membrane through the secretory pathway. ${ }^{37}$ The accumulation of these proteins at the plasma membrane leads to the formation of inclusions. This process starts with the appearance of small nuclei, which grow and further transform into larger cytoplasmic aggregates, as shown in Figure $2 .^{37-39}$ Similar to LB in the PD brain, some of the $\alpha$-syn inclusions in yeast are thioflavin-S positive and thus contain amyloid fibrils, ${ }^{38}$ whereas others represent merely $\alpha$-syninduced aggregates of cytoplasmic vesicles. ${ }^{39,40}$ Consistent with data obtained in mammalian cells and mouse brain, ${ }^{41}$ the binding of $\alpha$-syn to the yeast plasma membrane involves an interaction with detergent-resistant membrane domains, known as lipid rafts. ${ }^{42}$ In agreement with results from in vitro experiments, ${ }^{21}$ membrane binding in yeast is dependent on the $\mathrm{N}$-terminal repeat region of $\alpha$-syn and is a prerequisite for the subsequent inclusion formation, mediated by the central hydrophobic domain. ${ }^{40,43-45}$ Hence, $\alpha$-syn mutations that perturb the membrane interaction also abrogate the propensity of $\alpha$-syn to form inclusions. These not only include 
Table 1 Main topics described in yeast in connection to expression of human $\alpha$-synuclein

\begin{tabular}{|c|c|}
\hline Process & Description \\
\hline Membrane interaction & $\begin{array}{l}\text { General }^{37,38,46} \\
\text { Lipid raft interaction }{ }^{42} \\
\text { Membrane-binding properties and } \\
\text { inclusion formation }^{40,43-45}\end{array}$ \\
\hline Vesicular trafficking & $\begin{array}{l}\text { General }{ }^{42,46,55,70} \\
\text { ER-to-Golgi traffic } \\
\text { Secretory pathway } \\
\text { Vacuolar protein sorting } \\
\text { Vac,58,66 } \\
\text { Endocytosis }\end{array}$ \\
\hline $\begin{array}{l}\text { Cytoskeleton assembly } \\
\text { Protein QC systems }\end{array}$ & $\begin{array}{l}\text { Tubulin, actin } \\
\text { General }^{42,55,58,50,55,58,66}\end{array}$ \\
\hline & $\begin{array}{l}\text { Heat-shock proteins, } \\
\text { chaperones }^{37,42,55,57,58} \\
\text { Ubiquitin-proteasome }^{37,38,42,46,47,58,64,70} \\
\text { ERAD }^{39,69} \\
\text { Autophagy }^{38,42,55,66}\end{array}$ \\
\hline Protein synthesis & $\begin{array}{l}\text { General }{ }^{42,55,70} \\
\text { Protein synthesis inhibition } \\
\text { N-terminal acetylation } \\
\text { Protein phosphorylation } \\
\text { Prot }^{42,54}\end{array}$ \\
\hline Signal transduction & $\begin{array}{l}\text { General }{ }^{42,55,70} \\
\text { Casein kinase, polo-like kinase, SGK } \\
\text { kinase }^{42,54,55} \text {, }\end{array}$ \\
\hline Lipid metabolism & $\begin{array}{l}\text { General } \\
\text { Phospholipase } D^{46,70,80} \\
\text { Sterol biosynthesis }^{42,55}\end{array}$ \\
\hline Stress responses & $\begin{array}{l}\text { General }{ }^{42,70} \\
\text { Oxidative stress } \\
\text { Nitrosative stress } s^{55} \\
\text { Metal ions }{ }^{38,54,72} \\
\text { Glutathione }^{42,57}\end{array}$ \\
\hline Cell death & $\begin{array}{l}\text { Mitochondrial activity }{ }^{42,79} \\
\text { Aging } \\
\text { Apoptosis }^{42,64,79} \\
\text { Necrosis }^{79}\end{array}$ \\
\hline
\end{tabular}

mutations that disrupt the $\mathrm{N}$-terminal $\alpha$-helix formation, such as the clinical A30P mutation, but also mutations that prevent $\mathrm{N}$-terminal acetylation, as discussed below. ${ }^{42-44}$ Note that the A30P mutant is deficient in nucleation but that this protein can be forced to form inclusions by increasing the lipid content or by providing the necessary nuclei through coexpression of WT-syn, as illustrated in Figure 2. ${ }^{38}$

As expression of WT-syn or the A53T mutant, but not of the A30P mutant, results in a pronounced growth phenotype, it was suggested that the $\alpha$-syn inclusions would be toxic to yeast cells. ${ }^{37,46}$ However, later reports showed that $\alpha$-syn toxicity is dependent on the genetic background as in certain yeast strains the cells can be loaded with $\alpha$-syn inclusions without showing a significant growth defect. ${ }^{38,47}$ Moreover, cells of the fission yeast Saccharomyces pombe show extensive $\alpha$-syn inclusion formation without any toxicity. ${ }^{48}$ As WT-syn and the A53T mutant do not target the plasma membrane in $S$. pombe cells and, as such, behave in a manner similar to the A30P mutant in $S$. cerevisiae cells, it was hypothesized that the $\alpha$-syn-derived toxicity would correlate better with the membrane binding capacity rather than with the fibrillization rate of the protein. ${ }^{48}$ This was confirmed by the analysis of different $\alpha$-syn mutants in baker's yeast. $^{43,44}$

Next, toxicity of $\alpha$-syn in yeast is determined by posttranslational modifications. Similar as in PD brain, ${ }^{23} \alpha$-syn is subject of $\mathrm{N}$-terminal acetylation in yeast, a modification catalyzed by the $\mathrm{N}$-terminal acetyltransferase $\mathrm{B}$ complex (NatB) that is required for the proper $\alpha$-syn membrane interaction. Interestingly, WT-syn shows no cytotoxicity when expressed in a strain lacking NatB activity. ${ }^{42}$ In addition, $\alpha$-syn is also phosphorylated at ser-129 in PD brain ${ }^{23}$ but it is still

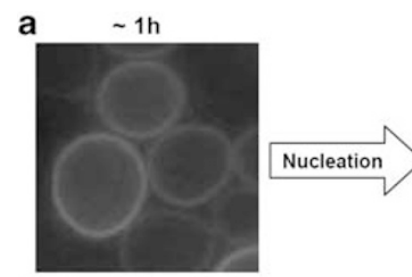

Membrane localization

b

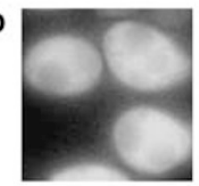

GFP-A30P

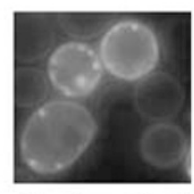

Seeding effect GFP-A30P $\sim 12 \mathrm{~h}$

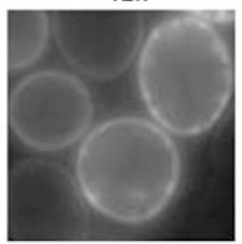

Small inclusions membrane connected

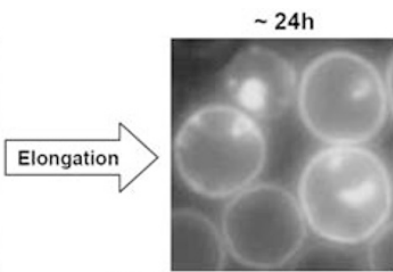

Large cytoplasmic/membrane inclusions

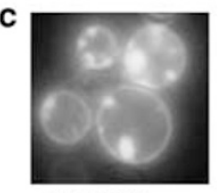

GFP-WT-syn

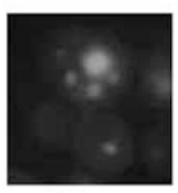

WT-syn

Thioflavin S

Figure 2 Expression of $\alpha$-synuclein in the yeast Saccharomyces cerevisiae. (a) Shown is a time- and expression-dependent redistribution of wt-synuclein-EGFP fusion proteins in pho85 cells at 1,12 and $24 \mathrm{~h}$ after induction of its expression. Initially, $(1 \mathrm{~h})$ wt-synuclein is localized at the plasma membrane. On prolonged induction (12 h), wt-synuclein starts to form nuclei and small membrane localized inclusions. These inclusions often convert into larger cytoplasmic inclusions at later time points ( $24 \mathrm{~h}$ ). A similar redistribution is found for A53T-syn (data not shown). (b) In contrast, the A30P mutant is exclusively located in the cytoplasm and does not give rise to any inclusions. Interestingly, coexpression of native wt-synuclein with the A30P-EGFP fusion protein results in the formation of GFP-positive inclusions, indicating that the A30P mutant can form inclusions on the nuclei provided by wt-syn. (c) Thioflavin-S staining confirms the presence of $\beta$-sheeted $\alpha$-synuclein aggregates in pho85 $\Delta$ cells overexpressing either native or EGFP-fused wt-syn. Adapted from Zabrocki et al. ${ }^{38}$ with permission of the publisher 
controversial whether this contributes to generation of toxic $\alpha$-syn species. ${ }^{49}$ Several kinases have been proposed to mediate this phosphorylation, including casein kinases 1 and 2,50 the polo-like kinase PLK2 ${ }^{51}$ and, most recently, LRRK2. ${ }^{52}$ In yeast, phosphorylation of $\alpha$-syn by CK-I and CK-II casein kinases has been established and deletion of either one of the two plasma membrane resident CK-I kinases, Yck1 or Yck2, results in reduced $\alpha$-syn toxicity. ${ }^{42}$ This is consistent with data obtained for the pharmacological inhibition of casein kinase 2 in mammalian cells. ${ }^{33,53}$ In contrast, deletion of the vacuolar localized CK-I kinase, Yck3, enhances $\alpha$-syn inclusion formation ${ }^{42}$ and its overexpression protects yeast cells from $\alpha$-syn toxicity, similar to overexpression of its human ortholog CSNK1G3 in rat primary neuron cultures. ${ }^{54,55}$ Overexpression of the polo-like kinase Cdc5 also suppresses $\alpha$-syn toxicity in yeast. This is again similar to the effect obtained by overexpression of its human ortholog PLK2 in dopaminergic neurons of Caenorhabditis elegans and rat primary neuron cultures. ${ }^{54}$ Interestingly, pharmacological inhibition or knockdown of PLK2 is known to sensitize mammalian cells to apoptotic stimuli. ${ }^{53,56}$

As summarized in Table 1, several groups used the $\alpha$-synmediated growth phenotype or $\alpha$-syn localization as read out for selective and genome-wide genetic screenings aiming to identify genes and processes that could modulate the $\alpha$-syninduced toxicity in yeast. Some of these processes were further analyzed in depth and will be discussed below. These include protein biosynthesis and protein QC systems, vesicular traffic, and oxidative stress responses.

\section{$\alpha$-Syn Toxicity and the Role of Protein QC Systems in Yeast}

The involvement of protein QC by molecular chaperones in conveying $\alpha$-syn toxicity in yeast was evidenced by the observations that deletion of individual chaperones enhances $\alpha$-syn inclusion formation, ${ }^{42}$ whereas a mild heat shock, treatment with geldanamycin, a pharmacological activator of the heat-shock response or overexpression of chaperones protects yeast cells against $\alpha$-syn-induced toxicity. ${ }^{37,57,58}$ These data nicely recapitulate results obtained with transgenic flies ${ }^{59,60}$ and mice. ${ }^{61,62}$ Recently, the protein Gip2 was also identified as a multicopy suppressor of $\alpha$-syn toxicity that acts by triggering a heat-shock response in yeast. ${ }^{55} \mathrm{Gip} 2$ is a putative regulator of the Glc7-Gac1 protein phosphatase complex, a known activator of the heat-shock transcription factor Hsf1. ${ }^{63}$ Interestingly, the expression of $\alpha$-syn itself triggers transcriptional induction of heat-shock proteins in wild-type yeast cells. However, this effect is by far less than the heat-shock response triggered by thermal stress and therefore apparently not sufficient to cope with the accumulating misfolded protein. ${ }^{37}$

The connection between $\alpha$-syn toxicity and the UPS system was already evident in the first study reporting on the yeast $P D$ model, because many $\alpha$-syn inclusions in yeast cells were found to be immunoreactive with an antibody directed against ubiquitin. Moreover, expression of $\alpha$-syn was shown to trigger impairment of the proteasome. ${ }^{46}$ These data were extended by the observation that the reduced proteasome activity, triggered by $\alpha$-syn in yeast, is neither due to changes in the cellular proteasome content nor to inhibition of individual peptidases. Yet, it was found to be the result of an altered proteasome composition, which occurs together with a more general decrease in protein synthesis, a phenomenon the authors hypothesized to be linked to ER stress. ${ }^{64}$ Interestingly, these studies reported proteasomal impairment with WT-syn as well as with the A30P mutant. In fact, the latter seemed to be the most potent inhibitor. ${ }^{64}$ Given that the A30P mutant fails to form inclusions and is mainly cytoplasmic, it can be assumed that proteasomal impairment is triggered by soluble protein conformers. In this context, it should be noted that soluble oligomeric forms of WT-syn, the A53T and the A30P mutants have been shown in yeast. ${ }^{42,58}$ The consequence of failure of the UPS system on the behavior of $\alpha$-syn was documented by analysis of specific proteasomal mutants $^{37,47}$ and on addition of the proteasomal inhibitor, lactacystin. $^{38}$ Both approaches showed that proteasomal impairment enhances the accumulation and inclusion formation of wild-type and mutant $\alpha$-syn, including the A30P mutant, which in proteasomal mutants gained toxicity. Obviously, this reciprocal effect leads to a vicious cycle that might become overwhelming to the other protein QC systems as well.

To compensate for proteasomal impairment or in case of exceeded proteasome capacity, misfolded proteins are degraded by an autophagic pathway that involves the lysosome in higher eukaryotes and the vacuole in yeast. This pathway is also responsible for clearance of oligomeric aggregates of $\alpha$-syn, which cannot be accessed by the proteasome. ${ }^{65}$ As in mammalians, autophagy in yeast is induced by the TOR inhibitor rapamycin and such a treatment was initially shown to significantly reduce $\alpha$-syn inclusions in the yeast PD model. ${ }^{38}$ However, a very recent study identified the TOR interactor Lst8 and the downstream TOR effector Sit4 as multicopy $\alpha$-syn toxicity modulators, and this study reported that rapamycin treatment leads to increased $\alpha$-syn toxicity in yeast. ${ }^{55}$ The latter is difficult to reconcile with clearance of $\alpha$-syn inclusions unless one would assume that clearance would lead to higher levels of soluble and toxic $\alpha$-syn conformers, for instance, because of less nuclei. Even more puzzling is the observation that WT-syn and the A53T mutant do not enter the vacuolar lumen in yeast, at least not as GFP fusion, and that the native proteins even trigger a vacuolar fusion defect. ${ }^{42}$ The A30P mutant does not elicit this vacuolar fusion defect and, interestingly, this mutant can be driven into the vacuolar lumen on overexpression of the $\alpha$-syn toxicity suppressor Ypp1, a protein that mediates traffic to the vacuole through the endocytic pathway but not through autophagy. ${ }^{66}$ Hence, it is clear that more detailed studies are required to fully understand how autophagy could interfere with $\alpha$-syn toxicity in yeast.

Recently, Ypk9 was identified as yet another suppressor of $\alpha$-syn toxicity. ${ }^{54,55}$ This protein is the yeast ortholog of PARK9 or ATP13A2, a lysosomal P-type ATPase for which it was hypothesized that it could be involved in lysosomal degradation of $\alpha$-syn. ${ }^{67}$ Although Ypk9 localizes at the vacuole and reduces intracellular $\alpha$-syn inclusions when overexpressed, it does not affect the steady-state levels of $\alpha$-syn. Instead, Ypk9 protects yeast cells from manganese exposure, ${ }^{54}$ a metal ion known as a risk factor for PD and shown to accelerate the $\alpha$-syn fibrillization rate in vitro. ${ }^{68}$ 


\section{$\alpha$-Syn Toxicity and Vesicular Trafficking in Yeast}

As $\alpha$-syn transits the secretory pathway to reach the plasma membrane in yeast, the first compartment encountered is the ER. Consistently, one of the earliest defects incited by WT-syn and the A53T mutant is the obstruction of ERAD substrates in the ER, as depicted in Figure 3 . This defect causes ER stress and is due to impaired docking and fusion of ER-derived vesicles to the Golgi membranes. ${ }^{69}$ In consequence, vesicles from the peripheral ER start to accumulate near the plasma membrane where they appear to cluster with vesicles from other trafficking routes. Such clustered vesicles are also evident around the perimeter of LB and may represent an early stage of LB formation in a PD brain. ${ }^{39,40}$ Interestingly, the $\alpha$-syn-induced blockage of ER-to-Golgi transport and the concomitant toxicity can be suppressed by overexpression of Ypt1, the yeast Rab-GTPase specific for ER-to-Golgi traffic. ${ }^{69}$ Similar observations have been made in C. elegans, where the $\alpha$-syn-induced degeneration of dopaminergic neurons is rescued on overexpression of murine Rab1, the ortholog of Ypt1, the overexpression of human RAB8A, the homolog of yeast Sec4 required for vesicular docking at the plasma membrane, or the overexpression of human RAB3A, which is neuron-specific and synapticlocalized. ${ }^{39,69}$

In addition, endocytosis is hampered by expression of WTsyn or the A53T mutant in yeast and this triggers toxicity mainly because of the obstruction of post-vesicle internalization steps and defects in vacuolar fusion. ${ }^{42,46}$ As depicted in Figure 3 , these defects further seem to enhance the recycling from $\alpha$-syn-loaded endosomes back to the plasma membrane. It has been speculated that this process accelerates the accumulation of $\alpha$-syn at the plasma membrane, thereby allowing the protein to reach its critical concentration necessary for self-assembly and inclusion formation. ${ }^{42}$

Besides ER-to-Golgi transport, the secretory and the endocytic pathways, $\alpha$-syn is likely to affect, either directly or indirectly, other vesicular trafficking routes as well. This is

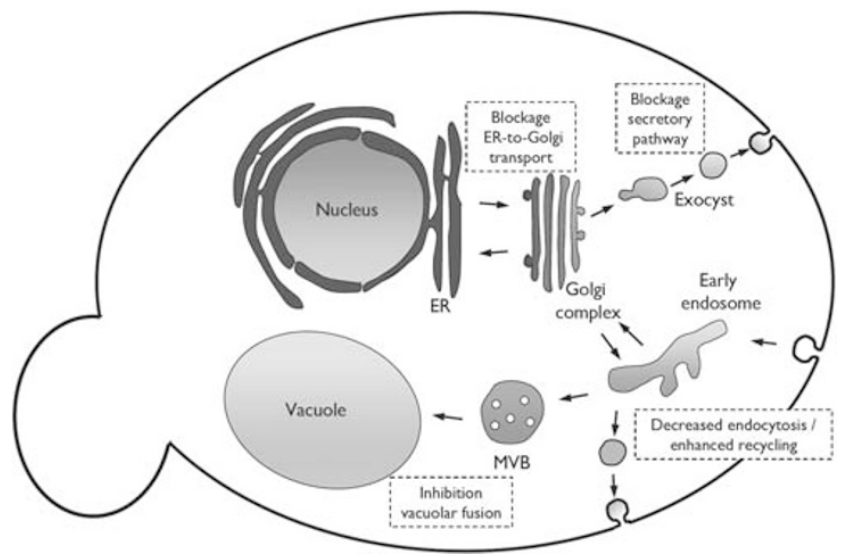

Figure $3 \alpha$-Synuclein toxicity in yeast by interference with vesicular trafficking. Shown is a schematic representation of the main vesicular trafficking routes in yeast. As indicated in the boxed insets, $\alpha$-syn expression affects yeast vesicular trafficking at multiple levels. The ER-to-Golgi transport and secretory pathway are blocked, whereas endocytosis is delayed. On the other hand, plasma membraneassociated $\alpha$-syn that has been endocytosed cannot be degraded in the vacuole, but is rather recycled to the plasma membrane. See main text for references evidenced by the observation that genetic screenings, aiming to identify components interfering with $\alpha$-syn localization and/ or toxicity, led to the retrieval of proteins belonging to different vesicular sorting and tethering complexes. ${ }^{42,55,66,70}$

\section{$\alpha$-Syn Toxicity, Oxidative Stress and Cell Death in Yeast}

Given the importance of oxidative stress in the pathology of $\mathrm{PD}$, the yeast model has also been used to study the mutual effects of $\alpha$-syn toxicity and oxidative stress. For PD, metal ions are considered as major risk factors because of their ability to induce oxidative stress in combination with oligomerization and fibrillization of $\alpha$-syn. ${ }^{71}$ Two studies confirmed that treatment of yeast cells with ferrous ions triggered an increase in oxidative stress concomitant with enhanced inclusion formation and toxicity of $\alpha$-synn. ${ }^{38,72}$ One of these studies also identified the flavonoids quercetin and (-)-epigallocatechin-3gallate as compounds that efficiently counteract $\alpha$-syn toxicity in non-treated yeast cells. ${ }^{72}$ As both compounds have strong antioxidant properties, this indicates that $\alpha$-syn expression by itself augments oxidative stress in yeast, similar to what has been reported to occur in neuronal cells. ${ }^{73}$ This was confirmed in a more elaborate analysis that also revealed $\alpha$-synmediated induction of typical apoptotic markers in yeast, such as phosphatidylserine externalization and cytochrome $c$ release, in addition to increased ROS levels. ${ }^{57}$ Together, the above described results nicely illustrate that $\alpha$-syn toxicity and oxidative stress seed each other and that cells may be trapped in a self-amplifying loop.

The mechanistic details of $\alpha$-syn-induced ROS formation have not been analyzed in detail. However, a study on the induction of apoptotic cell death by accumulation of misfolded carboxypeptidase $Y$ within the lumen of the yeast ER showed that increased ROS levels result from a prolonged UPR activation. This activation triggers ROS production in the ER during the formation of disulfide bonds, which indirectly also stimulates ROS production in the mitochondria. ${ }^{10}$ Given that $\alpha$-syn impairs ERAD through blockage of ER-to-Golgi vesicular transport in yeast, it is more than likely that this UPR-dependent mechanism is one of the ROS-generating scenarios deployed by $\alpha$-syn. Interestingly, the process has recently been recognized in a mammalian cell model to be dependent on $\alpha$-syn phosphorylation. ${ }^{33}$

Nitrosative stress represents another burden leading to neuronal loss. ${ }^{74}$ Although yeast does not encode a canonical nitric oxide synthase, several proteins become S-nitrosylated on expression of WT-syn, an effect that goes along with upregulation of the disulfide isomerase Pdi1. ${ }^{55}$ In neuronal cells, PDI exerts a protective function against misfolded proteins and ER stress, but this property is lost when the protein becomes S-nitrosylated as in a PD brain. ${ }^{75}$ Again, this establishes a link between the protein folding machinery of the ER and $\alpha$-syn toxicity.

Contradictory results have been obtained in PD research with respect to the execution of cell death. Although more and more data are pointing to an involvement of the mitochondria, mainly because of the genetic linkage of PD to the mitochondrial localized proteins PINK1, Parkin and DJ-1, almost nothing conclusive is known about the cell death mechanisms induced by $\alpha$-syn. ${ }^{35,36}$ Research from the last 
decade has established that the intrinsic apoptotic pathway and its key regulators are well conserved from yeast to humans. However, yeast cells can execute this programmed cell death in a caspase-dependent or -independent manner. ${ }^{76}$ Only one caspase is encoded by yeast, that is Yca1, ${ }^{77}$ and the role of this protein for $\alpha$-syn-induced cell death was initially ambiguous. One study reported that cells lacking Yca1 have lower $\alpha$-syn-induced ROS levels, ${ }^{57}$ whereas another study showed these cells to display higher $\alpha$-syn toxicity. ${ }^{72}$ However, both studies analyzed exponentially growing cells and by now it is clear that besides its role in apoptosis, Yca1 fulfills regulatory functions in cell cycle control. ${ }^{78}$ More recently, $\alpha$-syn-induced cell death was analyzed in postmitotic chronologically aged yeast cells and the data conclusively showed that WT-syn and the A53T mutant induced both apoptosis and necrosis. ${ }^{79}$ This is in contrast to the A30P mutant, which does not affect the chronological life span significantly, as illustrated in Figure 4. Cell death induced by WT-syn required functional mitochondria but not Yca1, or the proapoptotic proteins Aif1 and $\mathrm{OMI} / \mathrm{HtrA} 2$, the latter being a known susceptibility factor for PD. ${ }^{79}$ Finally, autophagic cell death is another form of cell loss being considered in PD. ${ }^{35,36}$ However, the WT-syn-mediated cell death in yeast is independent of Atg5 and Atg6 and thus independent of autophagy. ${ }^{79}$

\section{Concluding Remarks}

In conclusion, it is clear that yeast represents a valuable cellular tool to confirm established and decipher new clues explaining the devastating pathological role of $\alpha$-syn in PD. Of course, the yeast cell-based model can only provide mechanistic insights as it does not allow study of the disease itself. Furthermore, as with all models, the yeast system has its restrictions. For instance, being a unicellular eukaryote, yeast cells miss several cellular processes directed toward intercellular communication or organismal development. Even in connection with $\alpha$-syn, such processes likely contribute to the etiology of PD. Indeed, in vivo $\alpha$-syn localizes almost exclusively to the synaptic terminals and the protein
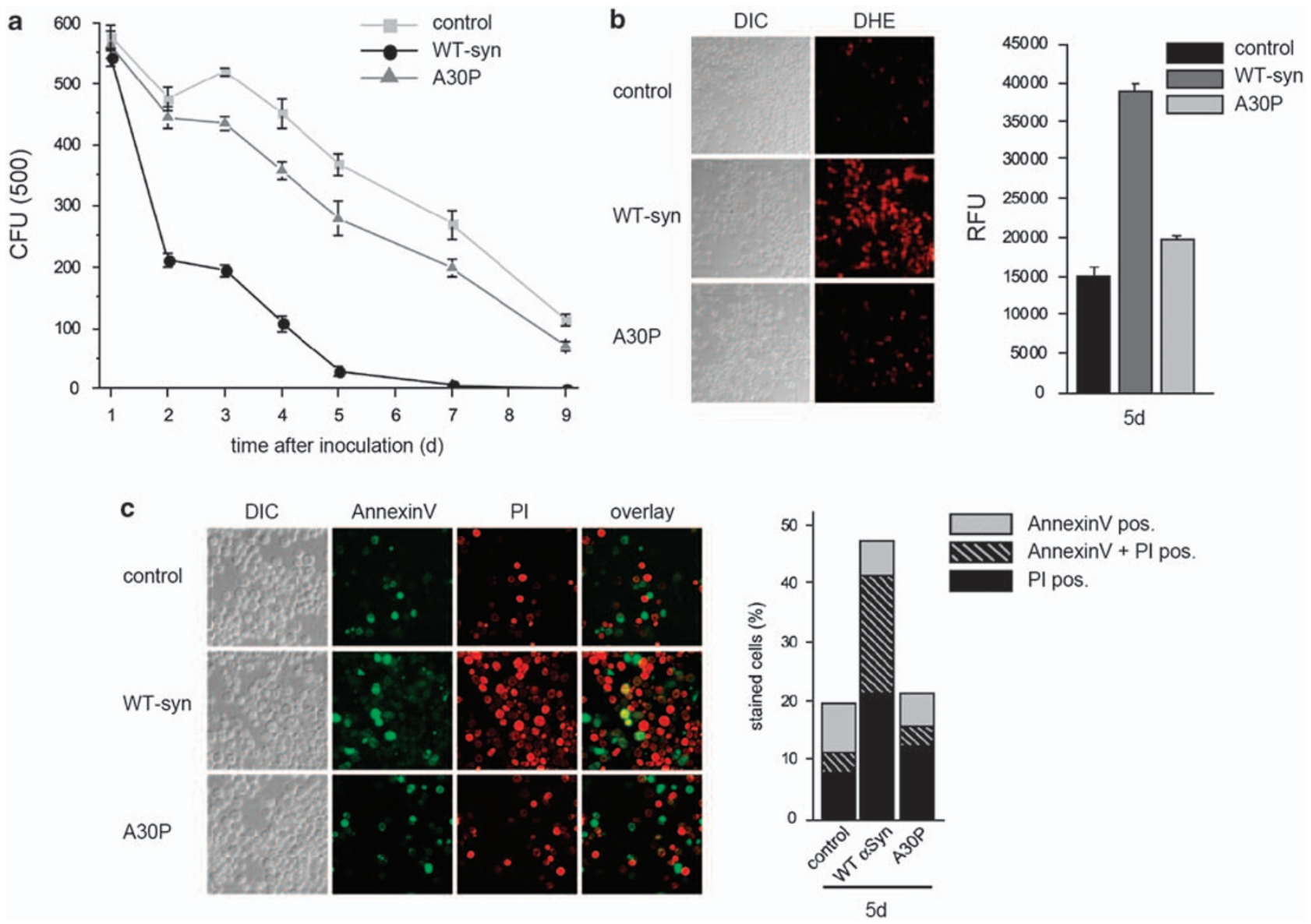

Figure 4 Apoptotic and necrotic cell death mediated by $\alpha$-synuclein in aged yeast cells. (a) In contrast to the A30P mutant, the expression of WT-syn dramatically reduces the chronological life span of yeast cells as determined by clonogenicity. The reduced chronological life span of cells expressing WT-syn is nicely paralleled by (b) increased ROS levels, as measured by DHE staining, and (c) more cells showing phosphatidylserine externalization and loss of membrane integrity, as measured by annexin V and PI staining, respectively. The latter discriminates between early apoptotic cells (annexin V positive), late apoptotic cells that already show signs of secondary necrosis (annexin $V$ and PI positive) and necrotic cells (PI positive). Shown are fluorescence microscopy pictures and quantifications of cells harvested at day 5 of aging. See Büttner et al. ${ }^{79}$ for technical details. CFU, colony forming units; RFU, relative fluorescence units; DIC differential interference contrast 
has been suggested to have a role in neuronal plasticity, synaptogenesis and neurotransmitter release. Perhaps this may be one of the reasons why the A30P mutation, which abolishes the synaptic localization of $\alpha-\operatorname{syn}^{41}$ and triggers loss of dopaminergic neurons in the PD brain, ${ }^{15}$ fails to show a severe $\alpha$-syn-induced toxicity in yeast. Hence, novel findings made in the yeast model are only indicative and must be confirmed in higher eukaryotic systems and eventually be validated in the context of the diseased human brain.

\section{Conflict of interest}

The authors declare no conflict of interest.

Acknowledgements. This work was supported by IWT-Vlaanderen (SBO NEURO-TARGET), the KU Leuven Research Fund (KU Leuven BOF-IOF), KU Leuven R\&D and the Marie Curie PhD Graduate School NEURAD.

1. Naidoo N. ER and aging-protein folding and the ER stress response. Ageing Res Rev 2009; 8: 150-159.

2. Meriin $A B$, Sherman MY. Role of molecular chaperones in neurodegenerative disorders. Int J Hyperthermia 2005; 21: 403-419.

3. Ding WX, Yin XM. Sorting, recognition and activation of the misfolded protein degradation pathways through macroautophagy and the proteasome. Autophagy 2008; 4: 141-150.

4. Limon-Pacheco J, Gonsebatt ME. The role of antioxidants and antioxidant-related enzymes in protective responses to environmentally induced oxidative stress. Mutat Res 2009; 674: 137-147.

5. Halliwell B. Proteasomal dysfunction: a common feature of neurodegenerative diseases? Implications for the environmental origins of neurodegeneration. Antioxid Redox Signal 2006; 8: 2007-2019.

6. Halliwell B. Oxidative stress and neurodegeneration: where are we now? J Neurochem 2006; 97: 1634-1658

7. Paschen W, Mengesdorf T. Endoplasmic reticulum stress response and neurodegeneration. Cell Calcium 2005; 38: 409-415.

8. Cebollero E, Reggiori F. Regulation of autophagy in yeast Saccharomyces cerevisiae. Biochim Biophys Acta 2009; 1793: 1413-1421.

9. Temple MD, Perrone GG, Dawes IW. Complex cellular responses to reactive oxygen species. Trends Cell Biol 2005; 15: 319-326.

10. Haynes CM, Caldwell S, Cooper AA. An HRD/DER-independent ER quality control mechanism involves Rsp5p-dependent ubiquitination and ER-Golgi transport. J Cell Biol 2002; 158: 91-101.

11. Hol EM, Scheper W. Protein quality control in neurodegeneration: walking the tight rope between health and disease. J Mol Neurosci 2008; 34: 23-33.

12. Koutsilieri E, Scheller C, Grunblatt E, Nara K, Li J, Riederer P. Free radicals in Parkinson's disease. J Neurol 2002; 249 (Suppl 2): ॥1- II5.

13. Chen Q, Thorpe J, Ding Q, El-Amouri IS, Keller JN. Proteasome synthesis and assembly are required for survival during stationary phase. Free Radic Biol Med 2004; 37: 859-868.

14. Fabrizio $P$, Longo VD. The chronological life span of Saccharomyces cerevisiae. Methods Mol Biol 2007; 371: 89-95.

15. Tofaris GK, Spillantini MG. Physiological and pathological properties of $\alpha$-synuclein. Cell Mol Life Sci 2007; 64: 2194-2201.

16. Yang YX, Wood NW, Latchman DS. Molecular basis of Parkinson's disease. Neuroreport 2009; 20: 150-156.

17. Larsen KE, Schmitz Y, Troyer MD, Mosharov E, Dietrich P, Quazi AZ et al. Synuclein overexpression in PC12 and chromaffin cells impairs catecholamine release by interfering with a late step in exocytosis. J Neurosci 2006; 26: 11915-11922.

18. Chandra S, Gallardo G, Fernandez-Chacon R, Schluter OM, Sudhof TC. Synuclein cooperates with CSP $\alpha$ in preventing neurodegeneration. Cell 2005; 123: 383-396.

19. Souza JM, Giasson BI, Lee VM, Ischiropoulos $\mathrm{H}$. Chaperone-like activity of synucleins. FEBS Lett 2000; 474: 116-119.

20. Golovko MY, Barcelo-Coblijn G, Castagnet PI, Austin S, Combs CK, Murphy EJ. The role of $\alpha$-synuclein in brain lipid metabolism: a downstream impact on brain inflammatory response. Mol Cell Biochem 2009; 326: 55-66.

21. Uversky VN. Neuropathology, biochemistry, and biophysics of $\alpha$-synuclein aggregation. J Neurochem 2007; 103: 17-37.

22. Hodara R, Norris EH, Giasson BI, Mishizen-Eberz AJ, Lynch DR, Lee VM et al. Functional consequences of $\alpha$-synuclein tyrosine nitration: diminished binding to lipid vesicles and increased fibril formation. J Biol Chem 2004; 279: 47746-47753.

23. Anderson JP, Walker DE, Goldstein JM, de Laat R, Banducci K, Caccavello RJ et al. Phosphorylation of ser-129 is the dominant pathological modification of $\alpha$-synuclein in familial and sporadic Lewy body disease. J Biol Chem 2006; 281: 29739-29752.
24. Li W, West N, Colla E, Pletnikova O, Troncoso JC, Marsh L et al. Aggregation promoting C-terminal truncation of $\alpha$-synuclein is a normal cellular process and is enhanced by the familial Parkinson's disease-linked mutations. Proc Natl Acad Sci USA 2005; 102 2162-2167.

25. Krishnan S, Chi EY, Wood SJ, Kendrick BS, Li C, Garzon-Rodriguez W et al. Oxidative dimer formation is the critical rate-limiting step for Parkinson's disease $\alpha$-synuclein fibrillogenesis. Biochemistry 2003; 42: 829-837.

26. Hardy J, Cai H, Cookson MR, Gwinn-Hardy K, Singleton A. Genetics of Parkinson's disease and parkinsonism. Ann Neurol 2006; 60: 389-398.

27. Olanow CW, Perl DP, DeMartino GN, McNaught KS. Lewy-body formation is an aggresome-related process: a hypothesis. Lancet Neurol 2004; 3: 496-503.

28. Tanaka M, Kim YM, Lee G, Junn E, Iwatsubo T, Mouradian MM. Aggresomes formed by $\alpha$-synuclein and synphilin- 1 are cytoprotective. J Biol Chem 2004; 279: 4625-4631.

29. Lashuel HA, Petre BM, Wall J, Simon M, Nowak RJ, Walz T et al. Synuclein, especially the Parkinson's disease-associated mutants, forms pore-like annular and tubular protofibrils. J Mol Biol 2002; 322: 1089-1102.

30. Hsu LJ, Sagara Y, Arroyo A, Rockenstein E, Sisk A, Mallory M et al. Synuclein promotes mitochondrial deficit and oxidative stress. Am J Pathol 2000; 157: 401-410.

31. Li WW, Yang R, Guo JC, Ren HM, Zha XL, Cheng JS et al. Localization of $\alpha$-synuclein to mitochondria within midbrain of mice. Neuroreport $2007 ; 18$ : 1543-1546.

32. Lindersson E, Beedholm R, Hojrup P, Moos T, Gai W, Hendil KB et al. Proteasomal inhibition by $\alpha$-synuclein filaments and oligomers. J Biol Chem 2004; 279: 12924-12934.

33. Sugeno N, Takeda A, Hasegawa T, Kobayashi M, Kikuchi A, Mori F et al. Serine 129 phosphorylation of $\alpha$-synuclein induces unfolded protein response-mediated cell death. J Biol Chem 2008; 283: 23179-23188.

34. Ryu EJ, Harding HP, Angelastro JM, Vitolo OV, Ron D, Greene LA. Endoplasmic reticulum stress and the unfolded protein response in cellular models of Parkinson's disease. $J$ Neurosci 2002; 22: 10690-10698.

35. Levy OA, Malagelada C, Greene LA. Cell death pathways in Parkinson's disease: proximal triggers, distal effectors, and final steps. Apoptosis 2009; 14: 478-500.

36. Yao Z, Wood NW. Cell death pathways in Parkinson's disease: role of mitochondria. Antioxid Redox Signal 2009; 11: 2135-2149.

37. Dixon C, Mathias N, Zweig RM, Davis DA, Gross DS. Synuclein targets the plasma membrane via the secretory pathway and induces toxicity in yeast. Genetics 2005; 170: 47-59.

38. Zabrocki P, Pellens K, Vanhelmont T, Vandebroek T, Griffioen G, Wera $S$ et al. Characterization of $\alpha$-synuclein aggregation and synergistic toxicity with protein tau in yeast. FEBS J 2005; 272: 1386-1400.

39. Gitler AD, Bevis BJ, Shorter J, Strathearn KE, Hamamichi S, Su LJ et al. The Parkinson's disease protein $\alpha$-synuclein disrupts cellular Rab homeostasis. Proc Natl Acad Sci USA 2008; 105: 145-150.

40. Soper JH, Roy S, Stieber A, Lee E, Wilson RB, Trojanowski JQ et al. Synuclein-induced aggregation of cytoplasmic vesicles in Saccharomyces cerevisiae. Mol Biol Cell 2008; 19: 1093-1103.

41. Fortin DL, Troyer MD, Nakamura K, Kubo S, Anthony MD, Edwards RH. Lipid rafts mediate the synaptic localization of $\alpha$-synuclein. J Neurosci 2004; 24: 6715-6723.

42. Zabrocki P, Bastiaens I, Delay C, Bammens T, Ghillebert R, Pellens K et al. Phosphorylation, lipid raft interaction and traffic of $\alpha$-synuclein in a yeast model for Parkinson. Biochim Biophys Acta 2008; 1783: 1767-1780.

43. Volles MJ, Lansbury Jr PT. Relationships between the sequence of $\alpha$-synuclein and its membrane affinity, fibrillization propensity, and yeast toxicity. J Mol Biol 2007; 366: 1510-1522.

44. Vamvaca K, Volles MJ, Lansbury Jr PT. The first $\mathrm{N}$-terminal amino acids of $\alpha$-synuclein are essential for $\alpha$-helical structure formation in vitro and membrane binding in yeast. $J \mathrm{Mol} B \mathrm{BiO}$ 2009; 389: 413-424.

45. Kim M, Jung W, Lee IH, Bhak G, Paik SR, Hahn JS. Impairment of microtubule system increases $\alpha$-synuclein aggregation and toxicity. Biochem Biophys Res Commun 2008; 365 : 628-635.

46. Outeiro TF, Lindquist S. Yeast cells provide insight into $\alpha$-synuclein biology and pathobiology. Science 2003; 302: 1772-1775.

47. Sharma N, Brandis KA, Herrera SK, Johnson BE, Vaidya T, Shrestha R et al. Synuclein budding yeast model: toxicity enhanced by impaired proteasome and oxidative stress. $J$ Mol Neurosci 2006; 28: 161-178.

48. Brandis KA, Holmes IF, England SJ, Sharma N, Kukreja L, DebBurman SK. Synuclein fission yeast model: concentration-dependent aggregation without plasma membrane localization or toxicity. J Mol Neurosci 2006; 28: 179-191.

49. Azeredo da Silveira S, Schneider BL, Cifuentes-Diaz C, Sage D, Abbas-Terki T, Iwatsubo $\mathrm{T}$ et al. Phosphorylation does not prompt, nor prevent, the formation of $\alpha$-synuclein toxic species in a rat model of Parkinson's disease. Hum Mol Genet 2009; 18: 872-887.

50. Okochi M, Walter J, Koyama A, Nakajo S, Baba M, Iwatsubo T et al. Constitutive phosphorylation of the Parkinson's disease associated $\alpha$-synuclein. J Biol Chem 2000; 275: 390-397.

51. Inglis KJ, Chereau D, Brigham EF, Chiou SS, Schobel S, Frigon NL et al. Polo-like kinase 2 (PLK2) phosphorylates $\alpha$-synuclein at serine 129 in central nervous system. J Biol Chem 2009; 284: 2598-2602. 
52. Qing $\mathrm{H}$, Wong W, McGeer EG, McGeer PL. Lrrk2 phosphorylates alpha synuclein at serine 129: Parkinson disease implications. Biochem Biophys Res Commun 2009; 387: 149-152.

53. Kragh CL, Lund LB, Febbraro F, Hansen HD, Gai WP, El-Agnaf $O$ et al. Synuclein aggregation and ser-129 phosphorylation-dependent cell death in oligodendroglial cells. J Biol Chem 2009; 284: 10211-10222.

54. Gitler AD, Chesi A, Geddie ML, Strathearn KE, Hamamichi S, Hill KJ et al Synuclein is part of a diverse and highly conserved interaction network that includes PARK9 and manganese toxicity. Nat Genet 2009; 41: 308-315.

55. Yeger-Lotem E, Riva L, Su LJ, Gitler AD, Cashikar AG, King OD et al. Bridging highthroughput genetic and transcriptional data reveals cellular responses to $\alpha$-synuclein toxicity. Nat Genet 2009; 41: 316-323.

56. Matthew EM, Yen TJ, Dicker DT, Dorsey JF, Yang W, Navaraj A et al. Replication stress, defective S-phase checkpoint and increased death in PIk2-deficient human cancer cells. Cell Cycle 2007; 6: 2571-2578.

57. Flower TR, Chesnokova LS, Froelich CA, Dixon C, Witt SN. Heat shock prevents $\alpha$-synucleininduced apoptosis in a yeast model of Parkinson's disease. J Mol Biol 2005; 351: 1081-1100.

58. Liang J, Clark-Dixon C, Wang S, Flower TR, Williams-Hart T, Zweig R et al. Novel suppressors of $\alpha$-synuclein toxicity identified using yeast. Hum Mol Genet 2008; 17: 3784-3795.

59. Fan $\mathrm{GH}$, Zhou $\mathrm{HY}$, Yang $\mathrm{H}, \mathrm{Chen} \mathrm{SD}$. Heat shock proteins reduce $\alpha$-synuclein aggregation induced by MPP+ in SK-N-SH cells. FEBS Lett 2006; 580: 3091-3098.

60. Auluck PK, Meulener MC, Bonini NM. Mechanisms of suppression of $\alpha$-synuclein neurotoxicity by geldanamycin in Drosophila. J Biol Chem 2005; 280: 2873-2878.

61. Klucken J, Shin Y, Masliah E, Hyman BT, McLean PJ. Hsp70 reduces $\alpha$-synuclein aggregation and toxicity. J Biol Chem 2004; 279: 25497-25502.

62. Shen HY, He JC, Wang Y, Huang QY, Chen JF. Geldanamycin induces heat shock protein 70 and protects against MPTP-induced dopaminergic neurotoxicity in mice. J Biol Chem 2005; 280: 39962-39969

63. Lin JT, Lis JT. Glycogen synthase phosphatase interacts with heat shock facto to activate CUP1 gene transcription in Saccharomyces cerevisiae. Mol Cell Biol 1999; 19: 3237-3245.

64. Chen Q, Thorpe J, Keller JN. Synuclein alters proteasome function, protein synthesis, and stationary phase viability. J Biol Chem 2005; 280: 30009-30017.

65. Pan T, Kondo S, Le W, Jankovic J. The role of autophagy-lysosome pathway in neurodegeneration associated with Parkinson's disease. Brain 2008; 131: 1969-1978.

66. Flower TR, Clark-Dixon C, Metoyer C, Yang H, Shi R, Zhang Z et al. YGR198w (YPP1) targets A30P $\alpha$-synuclein to the vacuole for degradation. J Cell Biol 2007; 177: 1091-1104.
67. Ramirez A, Heimbach A, Grundemann J, Stiller B, Hampshire D, Cid LP et al. Hereditary parkinsonism with dementia is caused by mutations in ATP13A2, encoding a lysosomal type 5 P-type ATPase. Nat Genet 2006; 38: 1184-1191.

68. Uversky VN, Li J, Fink AL. Metal-triggered structural transformations, aggregation, and fibrillation of human $\alpha$-synuclein. A possible molecular NK between Parkinson's disease and heavy metal exposure. J Biol Chem 2001; 276: 44284-44296.

69. Cooper AA, Gitler AD, Cashikar A, Haynes CM, Hill KJ, Bhullar B et al. Synuclein blocks ER-Golgi traffic and Rab1 rescues neuron loss in Parkinson's models. Science 2006; 313: 324-328

70. Willingham S, Outeiro TF, DeVit MJ, Lindquist SL, Muchowski PJ. Yeast genes that enhance the toxicity of a mutant huntingtin fragment or $\alpha$-synuclein. Science 2003; 302: 1769-1772.

71. Gaeta A, Hider RC. The crucial role of metal ions in neurodegeneration: the basis for a promising therapeutic strategy. Br J Pharmacol 2005; 146: 1041-1059.

72. Griffioen G, Duhamel H, Van Damme N, Pellens K, Zabrocki P, Pannecouque $\mathrm{C}$ et al. A yeast-based model of $\alpha$-synucleinopathy identifies compounds with therapeutic potential. Biochim Biophys Acta 2006; 1762: 312-318.

73. Junn E, Mouradian MM. Human alpha-synuclein over-expression increases intracellular reactive oxygen species levels and susceptibility to dopamine. Neurosci Lett 2002; 320: 146-150.

74. Uehara T. Accumulation of misfolded protein through nitrosative stress linked to neurodegenerative disorders. Antioxid Redox Signal 2007; 9: 597-601

75. Uehara T, Nakamura T, Yao D, Shi ZQ, Gu Z, Ma Y et al. S-nitrosylated protein-disulphide isomerase links protein misfolding to neurodegeneration. Nature 2006; 441: 513-517.

76. Madeo F, Carmona-Gutierrez D, Ring J, Buttner S, Eisenberg T, Kroemer G. Caspasedependent and caspase-independent cell death pathways in yeast. Biochem Biophys Res Commun 2009; 382: 227-231.

77. Madeo F, Herker E, Maldener C, Wissing S, Lachelt S, Herlan M et al. A caspase-related protease regulates apoptosis in yeast. Mol Cell 2002; 9: 911-917.

78. Lee RE, Puente LG, Kaern M, Megeney LA. A non-death role of the yeast metacaspase: Yca1p alters cell cycle dynamics. PLoS One 2008; 3: e2956.

79. Büttner $\mathrm{S}$, Bitto $\mathrm{A}$, Ring J, Augsten $\mathrm{M}$, Zabrocki $\mathrm{P}$, Eisenberg $\mathrm{T}$ et al. Functional mitochondria are required for $\alpha$-synuclein toxicity in ageing yeast. J Biol Chem 2008; 283 : 7554-7560.

80. Rappley I, Gitler AD, Selvy PE, LaVoie MJ, Levy BD, Brown HA et al. Evidence that $\alpha$-synuclein does not inhibit phospholipase D. Biochemistry 2009; 48: 1077-1083. 